\title{
Directions and practical tools for professional education quality increase (the case of tourism industry of the Republic of Kazakhstan)
}

\author{
Saulesh A. Kalenova ${ }^{1}$, Gulzhan K. Yerubayeva ${ }^{1}$, Dina I. Razakova ${ }^{1}$, Bahytgul M. \\ Demeuova $^{1}$, Denis Ushakov ${ }^{2, *}$ \\ ${ }^{1}$ Turan University, Almaty, Kazakhstan \\ ${ }^{2}$ International College, Suan Sunandha Rajabhat University, Bangkok, Thailand
}

\begin{abstract}
The economic globalization in the century of competition increase assumes some new economic relations. In our opinion, one of the key points for state's competitive recovery is the domestic tourism development which, in turn, requires some changes in the skilled personnel training. The research objectives are in conduct and analysis of the results of sociological survey among travel companies' representatives working directly with graduates in the city of Almaty. In the course of the sociological research, we have applied the methods of generalizations, analyses, statistical distributions, expert judgments and comparisons. The conducted analytical research has allowed for studying the opinions of those specialists practicing in the tourist business and, thereupon, for making some conclusions and providing certain recommendations on the education quality improvement in training personnel for the tourist industry.
\end{abstract}

\section{Introduction}

Just few years ago no one could assume that the oil price would fluctuate so greatly.

The budget of the Republic of Kazakhstan, highly dependent on the oil prices decreased National Government interests to diversify the priorities of state development.

The zero hour showed that now it's time to deviate from the dependence on oil money and think seriously about the other industries of economy development which would really be able to rely upon when forecasting the national budgets' revenues [1]. And one of these prior industries is tourism that without so great expenses can bring sufficient income not only for the local and republican budgets, but also give many our compatriots a chance to live properly.

The economies of many countries exist and develop due to tourism $[3,4,5,6]$.

One of the priorities of the Kazakhstani economic development is tourism. That is why there is an attempt in the article to have a look at the Kazakhstani tourist business from the point of training highly-qualified personnel in 'Tourism' major.

\footnotetext{
*Corresponding author: denis.us@ssru.ac.th
} 
In Kazakhstan, the investors have only recently paid particular attention to this economic domain.

However, we are currently facing the poor quality of the tourist services.

This area employees' low professional level is felt more and more.

\section{Methodology of the study}

In order to study the quality of training by those higher educational institutions specialized in graduating bachelors in Tourism, we have conducted a sociological research. We interviewed 50 respondents related to travel companies in the city of Almaty. Those were the travel companies' directors (28\% of the respondents), their deputies (34\% of the respondents) and HR Managers (38\% of the respondents) entrusted with working with the newly arrived personnel.

The poll was conducted by questioning in the framework of implementation of grant project of the Ministry of Education and Science of the Republic of Kazakhstan "Integration Effects from the Economic Interaction at the Eurasian Economic Union".

The questionnaire contained 17 questions.

However, due to the article's limited volume, we present here the analysis of the most significant replies. In survey we were guided by the polling methodologies proposed by sociologists $[7,8,9]$.

For the research integrity, the questioning was conducted on anonymous basis, without the personal data collection. It allowed to obtain the most reliable and hard information [10, $11,12,13]$.

$36 \%$ out of the respondents were graduated from higher educational institutions in 'Travel Management' major.

The rest $64 \%$ have a higher education in other majors such as Finance (12\%), Pedagogical (8\%), International Policy (6\%), Psychology (6\%), Law (6\%), Management $(4 \%)$ and others.

$12 \%$ of surveyed population refused to identify their major.

Proposed question "The graduates of what higher educational institutions would you like to hire priory?" allowed us to identify the universities mostly preferred by employers.

Since the survey took place in the city of Almaty, those its universities were proposed the respondents to choose from, where specialists for the tourist industry have long been trained.

The poll found that (one respondent can choose more than one university from the list):

- 30 respondents prefer to hire the graduates from the Al-Farabi Kazakh National University

- 27 - mentioned the Kazakh Academy of Sports and Tourism

- 18 - Turan University

- 14 - The Almaty University (formerly International Academy of Business (IAB)

- 13 - The New Economic University named after T. Ryskulova (presently the Narkhoz University)

- 9 - KIMEP University (formerly Kazakhstan Institute of Management, Economics and Strategic Research)

- 6 - Kazakhstan German University

- 9 respondents considered that the place of employee study does not really matter.

It is interesting that such question as "Are you ready to hire university graduate without any work experience?" was replied positively by $64 \%$ of the respondents and only $36 \%$ of them prefer to hire the experienced specialists. 
At the same time, the question on the readiness to hire an inexperienced vocational college graduate was replied negatively by $66 \%$ of the respondents and only by $34 \%$ positively.

Respondents were proposed to choose the most popular problems among the graduates in 'Tourism' major (a multiple choice was proposed).

The greatest graduates' problem was the lack of the working process comprehension 49 respondents pointed this item;

The next relevant problem was the poor theoretical training (24 respondents);

The inexperienced candidates have the overstated expectations for wages (21 respondents);

The failure to do business correspondence (19 respondents);

The poor working motivation (17 respondents);

The bad grammar (gibberish) (18 respondents);

The lack of knowledge of sales in tourism (5 respondents);

The weakness of knowledge of geography ( 3 respondents);

The failure to communicate with customers ( 2 respondents).

The gaps in education are filled by work experience.

However, the solution of the above mentioned problems requires some employers' expenses.

That is why such question as "Is a major of a candidate for the position of a Travel Manager really important for his/her employment?" has a high importance. It was included in the questionnaire to know if it is really important to study in 'Tourism' major for further working in the tourist business.

The opinions are not similar. Slender majority $(51 \%)$ of the respondents consider that the candidate's education is important. The reason for such reply is, perhaps, that the today's graduates in 'Tourism' have no special advantages comparing to others humanitarian graduates.

Due to the very special professional requirements we proposed to evaluate the most important qualitative characteristics, by the respondents' opinion.

Each quality was evaluated from 1 (the highest mark, very important qualitative characteristic) to 10 (the lowest mark).

Most important qualitative characteristic as pointed are:

- degree of the young specialist (41 respondents);

- ability of high-speed information retrieval (39 respondents);

- the training favourability (33 respondents);

- responsibility (31 respondents);

- communicativeness (25 respondents);

- articulation (23 respondents);

- politeness (23 respondents);

- ability to handle stress (22 respondents);

- positive thinking (16 respondents).

Following characteristics were pointed by $9-15$ respondents: sense of duty; sense of humour; leadership skills; tidiness; creative thinking; managerial qualities.

Only 5 respondents mentioned the high importance of the master's degree. 24 respondents valued it at a low rate - from 8 to 10 . In our opinion, this is related to the fact that a master has no significant advantages to a bachelor working as a Travel Manager.

Let us proceed to the competencies. 


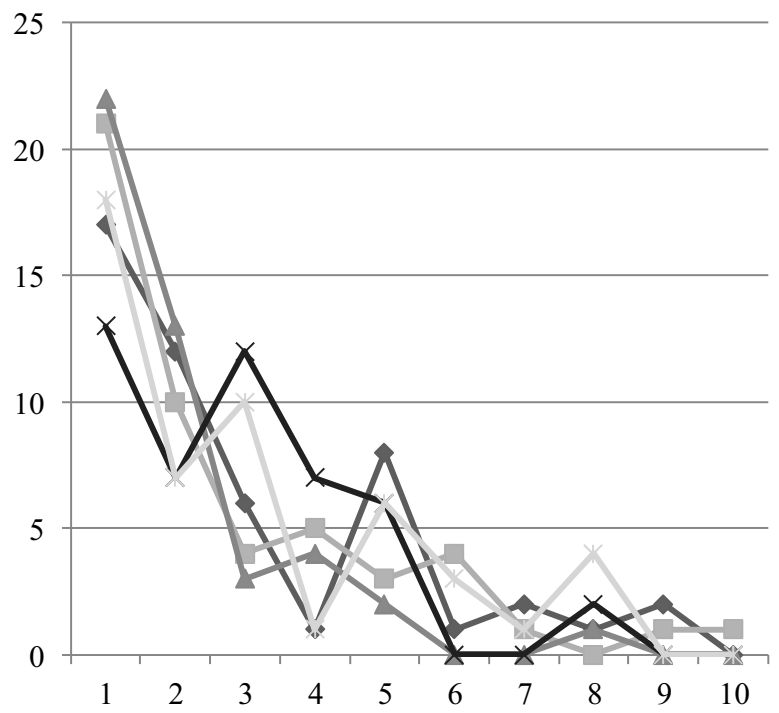

$\neg$ Knowledge of the airline reservation systems

- Knowledge of the major Kazakhstani tour operators

- Knowledge of the mass tourism destinations (Turkey, UAE, Thailand)

* Knowledge of the European countries

Knowledge of the English language

Fig. 1. Competency evaluation (Reply Group 1).

For convenience of the first insight into the data received in the course of the research, we divided all questions into 2 groups.

Figure 1 (the first group of the questions) shows the most important competencies to be possessed by the graduates in 'Tourism'. We proposed to evaluate the importance of the following knowledge: air tickets reservation, major tour operators, mass tourism destinations, European countries and English language.

According to the Kazakhstani statistical data, most tourist companies in the city of Almaty operate based on the outbound tours sales. That is why 22 respondents scored the necessity for the knowledge of the mass outbound tourism destinations (Turkey, UAE and Thailand) as ' 1 '. 13 respondents scored the knowledge of the mass tourism destinations as '2'. 1 respondent pointed to the unimportance of such knowledge. 5 respondents did not reply this question.

We proposed the question on the knowledge of the major Kazakhstani tour operators because the number of travel agencies far exceeds the number of tour operators. Therefore, when hiring a manager for working in a travel agency, it is important for him/her to know the operators he/she would have to deal with.

21 respondents agreed with such statement, having scored this competency as ' 1 '; 10 respondents scored it as ' 2 '.

Travel Manager's job is in dissoluble tied to the knowledge of the English language.

18 respondents agree with such an opinion and scored such competency as ' 1 '. It was scored as ' 2 ' by 7 respondents and 10 of them scored it as ' 3 '. 8 people did not consider the English language skills as a particularly important competency.

The knowledge of the air tickets reservation systems was scored as ' $1-5$ ' by 44 respondents, 17 scored it as ' 1 '. The air ticket sales are one of the tourist product constituents and most tourist companies try to provide their customers with such a service. At the same time, touroperators or travel agencies connect it with some risks and expenses, that is why the fact that part of respondents (6 people) consider such competency unimportant may be explained by tourist companies usage or co-working with specialized air-ticket sale agencies [14]. 
The knowledge of the European countries is scored by most respondents as the positive values from 1 to 5 (13 people scored it as the highest one).

Figure 2 shows the replies on the second group of questions.
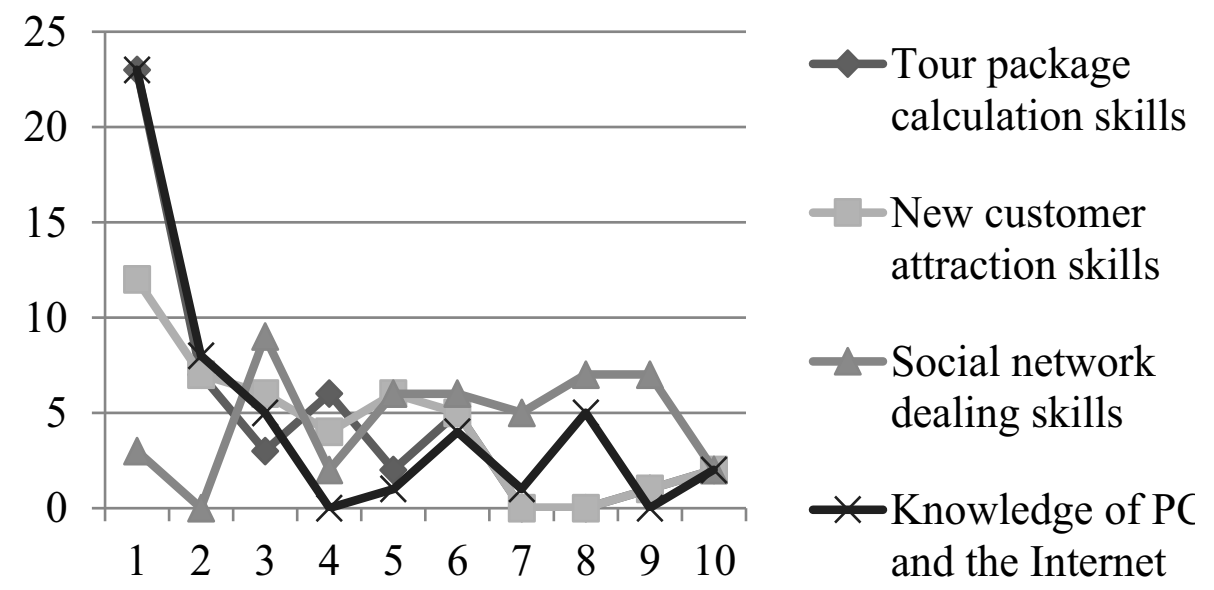

Fig. 2. Competency evaluation (Reply Group 2).

The tourpackage calculation skills were scored as the top by 23 respondents. The seven of them scored such skills as ' 2 '.

From there it may be concluded that it is necessary to develop such competency in the course of Travel Managers training.

It is interesting that employers pay not much attention to the new customer attraction skills. Such competency is considered very important by 12 people only. 7 respondents scored such skills as ' 2 '. 3 respondents consider that such competency is not important at all.

It was proposed to evaluate the following competency: proficiency in PC and the Internet, since these, to our mind, are the integral skills of a Travel Manager (Figure 2). 23 respondents agreed with our opinion and scored such skills as ' 1 '. 11 respondents scored such competency as ' $5-8$ '.

The social network dealing skills is a great addition to the major competencies. Travel agencies often consist of 2-3 managers and it does not allow hiring a marketing specialist. That is why the managers, upon the availability of such skills, may perform successfully the marketing work. However, the tour-operators' or travel agencies' CEOs think a bit differently. Only three respondents scored such skills as ' 1 '. It was considered as a quite important quality by 9 respondents. 19 people scored the values from 4 to 7 . Three polled respondents did not reply the question posed.

In the nest question of the questionnaire consisting of 2 parts, we proposed the respondents some items, which, in our opinion, should be added to the training program (the multiple choice was proposed).

At that, the respondents (the first part of the question) were proposed to point to those items unavailable in the current training program, but, to our mind, necessary for young specialist. Next, the replies were provided (Figure 3) in which the number of those agreed with our opinion can be seen.

We can see:

44 respondents recommend 'Amadeus Airline Reservation System' to be included in professional training program;

26 respondents recommended Principles of Successful Sales';

24 -'Business Communication Technology'; 
21 - 'Abacus Airline Reservation System';

15 -'Principles of Business Correspondence' and 'Principles of Law in Tourism';

The second part of the question is a proposal for the respondents to provide their own alternative disciplines, which, to the employers' mind, are extremely required (Figure 4).

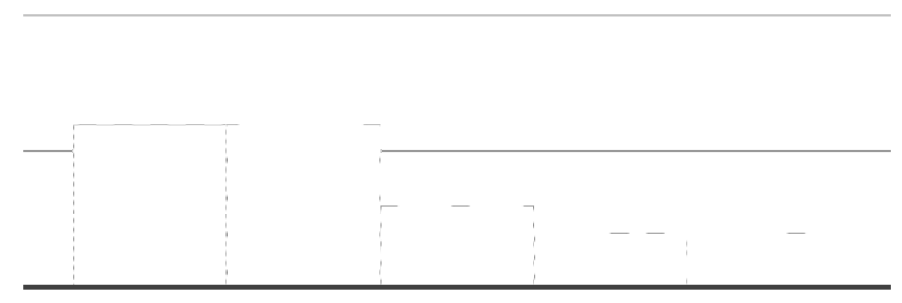

Corporate and

business tourism

English language

Kazakh language

Visa processing

Fig. 3. Disciplines proposed by employers to be studied at higher educational institutions.

6 respondents proposed 'Corporate and Business Tourism', as well as the English language study within the whole period of study.

3 respondents consider importance of studying Kazakh language.

2 - proposed to study the features of visas processing and the customer psychology.

\section{Conclusions}

The oil stock market collapse has shown that it is time for Kazakhstan to think on another economic development scenario. Kazakhstan, with such a vast territory coupled with its unique natural resources and, moreover, being in such an advantageous geographical location, has the essential opportunities for being included in the community of the 30 most competitive countries.

The key is the domestic tourist industry development.

However, one of the tourist industry development deterrents is the low quality of specialist training. The conducted sociological research showed us a number of the crucial points revealing the 'bottlenecks' in training travel managers.

To sum up the performed work we propose the following:

- It is necessary to decrease the number of studied disciplines that are not required for successful employment by employers' opinion;

- To increase the number of hours for studying most important disciplines (tour package calculations, individual courses on the most popular outbound tourism destinations, principles of sales, etc.);

- To apply the poly-lingual study methodology in practice;

- To comply reality with the credit education system requirements;

- To arrange a systematic efficient cooperation with tourist companies;

- To arrange an opportunity for the apprenticeship close to a tourist company's real work;

- To control the apprenticeship;

- To involve practitioners in the training process.

Universities should also conduct a yearly monitoring of opinions of those employers able to help in the quality training of travel managers.

Universities must train specialists required by the contemporary market, i.e., educational institutions must train the ready-to-work specialists here and now. To do that, it should be necessary to conduct and give encouragement to the conduct of various training quality research, with the employer adaptation. 


\section{References}

1. K. Bailey, Methods of social research (N.Y., Free Press, 1987)

2. J. Converse, P.S. Survey, Questions: Handcrafting the Standardized Questionnaire (Beverly Hills, CA, Sage Publications, 1986)

3. L. Harley, M. MacDonald, Doing sociology: A practical introduction (Basingstoke, 1993)

4. A. Privara, Geographical Journal 71(2), 161-180 (2019)

5. E. Vasyuta, D. Ushakov, The EUrASEANs: Journal on Global Socio-Economic Dynamics 5(18), 48-54 (2019)

6. K.S. Chon, L. Yu, International Hospitality Business (Management and Operations, Seoul, 1999)

7. C. Mills, Method of social research (University of London, 1994)

8. U. Muzafferl, Z. Schwartz, E. Sirakaya-Turk, Management Science in Hospitality and Tourism.Theory, Practice, and Applications (Istanbul, Apple Academic Press, 2016)

9. P. Brouder, S. Anton Clave, A. Gill, D. Ioannides, Tourism Destination Evolution (London, 2016)

10. A. Př́ivara, E. Rievajová, M.M. Yüceşahin, Migration Letters 16(4), 585-594 (2019)

11. I. Pavlenko, The EUrASEANs: Journal on Global Socio-Economic Dynamics 6(7), 92101 (2017)

12. V. Bogolyubov, V. Orlovskaya, Economics of tourism (Moscow, Academy, 2005)

13. Y. Voronov, Methods of data collection in sociology research (Moscow, Statistic, 1974)

14. S. Kalenova, Herald of Turan University 1, 134-138 (2015) 